\title{
Novel Predictors For New Onset Atrial Fibrillation After Typical Atrial Flutter Ablation: An Invasive Prospective Study
}

\section{Ermengol Vallès ( $\nabla$ ermengolvalles@mac.com )}

Institut Hospital del Mar d'Investigacions Mèdiques

Julio Martí-Almor

Institut Hospital del Mar d'Investigacions Mèdiques

\section{Nuria Grau}

Institut Hospital del Mar d'Investigacions Mèdiques

\section{Benjamin Casteigt}

Institut Hospital del Mar d'Investigacions Mèdiques

\section{Begoña Benito}

Institut Hospital del Mar d'Investigacions Mèdiques

\section{Sandra Cabrera}

Institut Hospital del Mar d'Investigacions Mèdiques

\section{Oscar Alcalde}

Institut Hospital del Mar d'Investigacions Mèdiques

\section{Eva Benito}

Institut Hospital del Mar d'Investigacions Mèdiques

\section{Deva Bas}

Institut Hospital del Mar d'Investigacions Mèdiques Javi Conejos

Institut Hospital del Mar d'Investigacions Mèdiques

Paula Cabero

Institut Hospital del Mar d'Investigacions Mèdiques

Cristina Soler

Institut Hospital del Mar d'Investigacions Mèdiques

\section{Xavier Duran}

Institut Hospital del Mar d'Investigacions Mèdiques

\section{Roger Fan}

Stony Brook University Hospital

\section{Jesus Jimenez}

Institut Hospital del Mar d'Investigacions Mèdiques 


\section{Research Article}

Keywords: Atrial fibrillation, Predictors, Cavotricuspid isthmus ablation, Risk score

Posted Date: June 21st, 2021

DOl: https://doi.org/10.21203/rs.3.rs-605959/v1

License: (c) (i) This work is licensed under a Creative Commons Attribution 4.0 International License. Read Full License 


\section{Abstract}

Purpose: Patients undergoing cavotricuspid isthmus (CTI) ablation for typical flutter (AFL) have a high incidence of new onset atrial fibrillation (AF). We aimed to analyze the incidence and predictors for new onset $\mathrm{AF}$ in this subset of patients to stratify thromboembolic risk.

Methods: Between 2016 and 2019, 70 patients without history of AF but with high-risk for developing AF, based on a recent AFL ablation or a high PACE score for AF risk, were prospectively included. All patients were monitored continuously by implantable loop recorder and followed by remote monitoring.

Results: Overall 48 patients were included after CTI ablation and 22 patients were included based on a high PACE score. New onset AF rate at 12 months was significantly higher in the AFL group compared to PACE group (56.3\% vs $22.7 \%, p=0.011)$. History of AFL was the only independent predictor for new onset AF (HR:3.82; 95\% Cl:1.46-10.03; $p=0.006)$ at a median follow-up of 12 months (Q1-Q3:4-19 months). In the AFL group, two very strong independent predictors for new onset AF were a PACE score ${ }^{3} 30$ (HR:6.9; 95\% Cl:1.71-27.91; $p=0.007)$ and HV interval ${ }^{3} 55$ (HR:11.86; 95\% Cl:2.57-54.8; $\left.p=0.002\right)$.

Conclusions: AFL is the most important predictor for new onset AF. In patients undergoing AFL ablation, a high PACE score and/or long HV interval predict even higher risk, and may be useful in decision for empiric long-term anticoagulation.

\section{Introduction}

Typical atrial flutter (AFL) is caused by a macroreentry in the right atrium and can be easily eliminated by cavotricuspid isthmus (CTI) catheter ablation, with a recurrence-rate of $6 \%$, decreasing to $1.5 \%$ if very specific techniques are used to assess complete CTI block [1-3]. However, after AFL ablation, new onset atrial fibrillation (AF) is diagnosed in 20 to $50 \%$ of cases at 2-3 years [4-13]. AF detection increases with more frequent monitoring and/or longer follow-up duration [8,9]. Several studies have identified predictors for AF after AFL ablation, but all are retrospective and non-invasive. On note guidelines aim for documentation of AF in the decision making process of continuation/discontinuation of long-term anticoagulation.

To date, the strongest predictors for AF after AFL ablation are left atrium dilatation [6,7], its surface ECG surrogate, the presence of advanced interatrial block [10], and its electrophysiological surrogate, the presence of a long interatrial conduction time [11]. Other variables associated with new onset AF are a high HATCH score [12], AF inducibility during the CTI ablation procedure [13], and the presence of obstructive sleep apnea (OSA) $[9,14]$.

In this study we sought to analyze the incidence and predictors for new onset AF after CTI ablation for typical AFL in a prospective manner, and compare with patients without AFL, but with high risk for AF based on the PACE calculator score. All patients underwent internal loop recorder (ILR) implantation or 
had preexisting implantable cardiac device with an atrial lead (CDAL) for continuous long-term monitoring.

\section{Methods}

\section{Study setting}

This study was supported by the 2014 La Marató de TV3 Foundation Program, which was dedicated to heart diseases and aims to promote biomedical research through the funds raised by Catalonian donations. The study was reviewed and approved by the Hospital del Mar ethics committee and all ablation procedures and ILR implantations were performed after written informed consent was obtained.

\section{Patient population}

Between 2016 and 2019, patients with high risk to develop AF and no history of AF were considered to be included in this prospective single-centre study. Patients were considered high risk if they had at least one of the two following conditions:

1. Patients presenting with typical $\mathrm{AFL}$, undergoing $\mathrm{CTI}$ ablation with resultant complete bidirectional block.

2. Patients with a PACE calculator risk score $\geq 30 \%$ for new onset AF at 3 years. The PACE calculator score uses a composite of 4 independent predictors for new onset AF (age, heart failure/cardiomyopathy, supraventricular ectopy $>0.2 \%$ or atrial tachycardia on $24 \mathrm{~h}$-holter monitoring (SVE), and PR interval) to predict new onset AF at 3 years [15]. This calculator is available at https://afibcalculator.com. An example can be seen in Fig. 1.

All patients underwent a 24h-holter monitoring to evaluate atrial ectopy, and an ILR implantation except for those already wearing a CDAL, and were followed by remote monitoring. The study protocol conforms to the ethical guidelines of the 1975 Declaration of Helsinki as reflected in a priori approval by our institution's human research committee.

\section{Study endpoints}

The introductory endpoint was the incidence of new onset AF after CTI ablation compared to other high risk patients with no history of AFL. Any AF episode of at least 2 minutes was defined as positive. The precise primary endpoint was the study of multiple clinical, echo, ECG, and electrophysiological variables to predict new onset AF after CTI ablation.

\section{Electrophysiological study, CTI ablation and ILR implantation.}

The description of the procedure has been described previously [16]. Briefly cavotricuspid isthmus ablation was performed under local anesthesia and conscious sedation. Anticoagulation therapy was not discontinued. Two diagnostic multipolar steerable $6 \mathrm{~F}$ catheters were placed through the right femoral 
vein into the low lateral right atrium and the coronary sinus ostium (CSO). A 7F irrigated-tip catheter was used for CTI mapping and ablation. Radiofrequency ablation was performed during atrial pacing from the CSO or during AFL. Established criteria for the diagnosis of bidirectional CTI complete block were assessed, including incremental pacing maneuvers [16-18]. Conduction parameters, including $\mathrm{AH}$ and HV interval were measured. During the same procedure, an ILR was placed under local anesthesia and antibiotic prophylaxis with Cefazolin.

\section{Long-term follow-up}

All antiarrhythmic drugs were discontinued after ILR implantation. Patients had follow-up in the outpatient clinics 2 months after the procedure and every 6 months thereafter for a minimum period of time of 1 year. Patients were monitored with monthly remote transmissions by means of Home Monitoring Service Center (Biotronik ILR) or Merlin.net (Abbott ILR).

\section{Statistical analysis}

Continuous variables are expressed as mean \pm SD. Comparisons between groups were performed using an unpaired Student $t$ test, a Chi-square test or a Fisher exact test analysis as appropriate. The primary end point was AF documentation, first of all taking into account the whole population and afterwards, restricted to the population having with previous AFL. Kaplan-Meier survival curves were performed to compare patients with and without previous AFL, using log-rank test to check differences between survival curves. Cox regression models were used to estimate hazard ratios associated to AF. Univariate and multivariate analysis were performed. Variable selection on multivariate analysis was based on previous knowledge (clinical criteria) and variables with p-values $<0.1$ on univariate analysis (both criteria combined). Finally, and restricted to the analysis of patients with previous AFL, optimal cutoffs points were calculated for the variables PACE calculator score and HV, using the Youden criteria: sample point that maximizes the Youden index (sensitivity + specificity -1 ). These dichotomized variables were also analyzed through Kaplan-Meier survival curves and included in the multivariate analysis. A p value of $\leq$ 0.05 was considered statistically significant. All statistical analyses were performed using STATA version 15.1 (StataCorp, College Station, TX, USA).

\section{Results}

\section{Population characteristics}

Between 2016 and 2019, 70 patients ( $79 \%$ male, $78.54 \pm 10.87$ years) with high risk to develop AF and no history of AF were included: 48 patients ( $85 \%$ male, $76.11 \pm 10.68$ years) were consecutive non-selected patients included after CTI ablation with complete bidirectional block (AFL group) independent of the PACE calculator risk score, and 22 patients ( $64 \%$ male, $80.59 \pm 10.74$ years) were included based on a high PACE calculator score (PACE group). Overall 60 patients (86\%) underwent an ILR implantation during admission, while the remaining 10 patients $(14 \%)$ had a previously implanted CDAL. There were either no complications related to the ablation procedure or to the ILR implantation. Patients with previous AFL had 
less comorbidities, including renal failure, hypertension, dyslipidemia, left ventricle hypertrophy, previous stroke, ischemic coronary disease and valvular disease (Table 1). As expected, the PACE calculator score was lower among patients with previous AFL (20.09 \pm 19.3 with AFL vs. $47.05 \pm 20.77$ without AFL; $p<$ 0.001), as the history of AFL was the only reason for them to be enrolled, whereas patients without AFL were selected for their higher PACE calculator score. For the same reason CHA2DS2-VASC score was higher in patients without AFL compared to those with AFL ( $4.5 \pm 1.4$ vs $2.7 \pm 1.6$, respectively; $p<0.001)$. No differences were observed in terms of ECG, echocardiography, Holter or polysomnography parameters between both groups. 
Table 1

Comparison of characteristics in patients who had prior AFL ablation and patients who did not, but had high-risk score for AF

$\begin{array}{llll}\begin{array}{l}\text { Total population }(n= \\ 70)\end{array} & \text { Without AFL } & \text { With AFL } & \begin{array}{l}\text { p- } \\ \text { value } \\ (n=22)\end{array} \\ (n=48) & \end{array}$

\section{Clinical variables}

\begin{tabular}{|lllll|}
\hline Age (years) mean (SD) & $78.54(10.87)$ & $80.59(10.74)$ & $76.11(10.87)$ & 0.079 \\
\hline BMI (kg/m2) mean (SD) & $30.10(5.51)$ & $29.92(4.17)$ & $30.18(5.99)$ & 0.885 \\
\hline Glom. F (ml/min) mean (SD) & $65.10(19.40)$ & $55.82(16.89)$ & $69.54(19.10)$ & 0.019 \\
\hline $\begin{array}{l}\text { Hemoglobin (mg/dL) mean } \\
\text { (SD) }\end{array}$ & $13.70(1.95)$ & $13.07(2.11)$ & $13.99(1.82)$ & 0.115 \\
\hline Hypertension & $55(78.5 \%)$ & $21(95.4 \%)$ & $34(70.8 \%)$ & 0.026 \\
\hline Tobacco use & $31(44.3 \%)$ & $7(31.8 \%)$ & $24(50 \%)$ & 0.303 \\
\hline Diabetes mellitus & $23(32.8 \%)$ & $7(31.8 \%)$ & $16(33.3 \%)$ & 1.000 \\
\hline Dyslipidemia & $39(55.7 \%)$ & $17(77.3 \%)$ & $22(45.8 \%)$ & 0.020 \\
\hline Ischemic disease & $21(30 \%)$ & $11(50 \%)$ & $10(20.8 \%)$ & 0.023 \\
\hline Valvular disease & $9(12.8 \%)$ & $7(31.8 \%)$ & $2(4.2 \%)$ & 0.003 \\
\hline Stroke & $7(10 \%)$ & $6(27.3 \%)$ & $1(2.1 \%)$ & 0.003 \\
\hline CHA2DS2-VASC & $3.2(1.8)$ & $4.5(1.4)$ & $2.7(1.6)$ & 0.001 \\
\hline PACE-Calc. mean (SD) & $28.41(23.28)$ & $47.05(20.77)$ & $20.09(19.30)$ & $<$ \\
\hline Polysomnography variables & & & & \\
\hline Snorer & $29(41.4 \%)$ & $8(27.6 \%)$ & $21(72.4 \%)$ & 0.610 \\
\hline Epworth. mean (SD) & $8.68(4.28)$ & $8.09(3.99)$ & $8.92(4.45)$ & 0.642 \\
\hline IAH. mean (SD) & $31.95(19.48)$ & $26.00(16.63)$ & $34.60(20.34)$ & 0.157 \\
\hline CT90\%. mean (SD) & $17.90(27.93)$ & $12.54(24.55)$ & $20.38(29.48)$ & 0.660 \\
\hline Echocardiography variables & & & & 0.481 \\
\hline LAD (mm) mean (SD) & $42.14(5.97)$ & $21.59(4.88)$ & $22.87(3.78)$ & 0.379 \\
\hline LAS (cm2) mean (SD) & $22.33(4.28)$ & & & \\
\hline
\end{tabular}

AF: atrial fibrillation; AFL: atrial typical flutter; AT: atrial tachycardia; BMI: body mass index; HM: 24hholter monitoring; ILR: internal loop recorder; LA: left atrium; LAD: left atrium diameter; LAS: left atrium surface; LVEF: left ventricle ejection fraction; LVH: left ventricle hypertrophy; SV: supraventricular. 


\begin{tabular}{|c|c|c|c|c|}
\hline & $\begin{array}{l}\text { Total population }(n= \\
\text { 70) }\end{array}$ & $\begin{array}{l}\text { Without AFL } \\
(n=22)\end{array}$ & $\begin{array}{l}\text { With AFL } \\
(n=48)\end{array}$ & $\begin{array}{l}\mathrm{p}- \\
\text { value }\end{array}$ \\
\hline LA dilatation & $45(64.3 \%)$ & $18(81.8 \%)$ & $27(56.3 \%)$ & 0.059 \\
\hline LVEF (\%) mean (SD) & $54.89(12.52)$ & $58.95(13.13)$ & $52.59(11.71)$ & 0.058 \\
\hline LVEF $<55 \%$ & $26(37.1 \%)$ & $8(36.4 \%)$ & $18(37.5 \%)$ & 1.000 \\
\hline \multicolumn{5}{|l|}{ Electrophysiological variables } \\
\hline AH interval (msec) mean (SD) & - & - & $\begin{array}{l}115.59 \\
(32.53)\end{array}$ & - \\
\hline HV interval (msec) mean (SD) & - & - & $51.77(8.40)$ & - \\
\hline PR interval (msec) mean (SD) & $194.63(43.67)$ & $\begin{array}{l}205.10 \\
(41.08)\end{array}$ & $\begin{array}{l}190.27 \\
(44.38)\end{array}$ & 0.239 \\
\hline $\begin{array}{l}\text { QRS duration (msec) mean } \\
\text { (SD) }\end{array}$ & $113.91(29.33)$ & $\begin{array}{l}117.35 \\
(38.03)\end{array}$ & $\begin{array}{l}112.48 \\
(25.19)\end{array}$ & 0.898 \\
\hline SV ectopy $>0.2 \%$ at $24 \mathrm{~h}-\mathrm{HM}$ & $23(32.8 \%)$ & $10(45.4 \%)$ & $13(27 \%)$ & 0.172 \\
\hline Atrial Tachycardia at $24 \mathrm{~h}-\mathrm{HM}$ & $25(35.7 \%)$ & $9(40.9 \%)$ & $16(33.3 \%)$ & 0.597 \\
\hline $\begin{array}{l}\text { SV ectopy }>0.2 \% \text { or AT at } 24 \mathrm{~h}- \\
\text { HM }\end{array}$ & $36(51.4 \%)$ & $13(59.1 \%)$ & $23(47.9 \%)$ & 0.446 \\
\hline AT at ILR & $16(22.8 \%)$ & $4(18.2 \%)$ & $12(25 \%)$ & 0.760 \\
\hline Bradycardia at ILR & $15(21.4 \%)$ & $5(22.7 \%)$ & $10(20.8 \%)$ & 1.000 \\
\hline
\end{tabular}

\section{Typical atrial flutter is the strongest predictor for new onset AF}

When examining the entire cohort, the only two variables associated with new onset AF were the history of previously ablated typical AFL and the presence of SVE. Interestingly CHA2DS2-VASC score was not associated to new onset $\mathrm{AF}(3.3 \pm 1.6$ in patients without $\mathrm{AF}$ at follow-up vs $3.1 \pm 2$ in patients with $\mathrm{AF}$ at follow-up; $p=0.61$ ). Among patients with $A F L, 56.3 \%$ developed new onset $A F$, vs $22.7 \%$ of patients without AFL $(p=0.011)$. Concerning atrial ectopy, among patients with SVE $58.3 \%$ developed new onset $A F$, vs $32.4 \%$ of patients without SVE $(p=0.039)$. Survival analyses demonstrated AFL as the only predictor for new onset AF at median follow-up of 12 months (Q1-Q3: 4-19 months; HR: 3.82; 95\% Cl: 1.46-10.03; $p=0.006$ ). Multivariate analyses, including PACE calculator score, LA enlargement, and hypertension confirmed AFL as the only predictor (see Table 2). 
Table 2

Multivariate analysis of predictors for $\mathrm{AF}$ in the entire cohort

\begin{tabular}{|lcl|}
\hline & HR (95\% IC & p-value \\
\hline PACE calculator & $1.02[1.00 ; 1.03]$ & 0.076 \\
\hline Hypertension & $1.17[0.49 ; 2.78]$ & 0.728 \\
\hline LA dilatation & $1.44[0.65 ; 3.21]$ & 0.370 \\
\hline AFL & $5.96[2.01 ; 17.73]$ & 0.001 \\
\hline AF: atrial fibrillation; AFL: atrial typical flutter; LA: left atrium
\end{tabular}

Figure 2 shows the survival curve for freedom from AF incidence in relation to the presence of AFL.

\section{Predictors for new onset AF in patients with previous AFL}

Focusing only on patients with previous AFL ablation, Table 3 shows the characteristics of patients with vs without new onset AF at follow-up. Interestingly SVE remains as the only variable associated with AF in this subgroup of patients ( $73.9 \%$ of patients with SVE vs $26.1 \%$ without SVE; $p=0.023$ ). 
Table 3

Characteristics of patients who underwent AFL ablation who developed new onset AF

$$
\begin{array}{llll}
\text { Total } A F L \text { group }(n= & \left.\begin{array}{l}
\text { No } A F \\
\text { 48 }
\end{array}\right)
\end{array}\left(\begin{array}{ll}
n= & \left.\begin{array}{l}
\text { New onset } A F \\
27
\end{array}\right)
\end{array} \quad \begin{array}{l}
p- \\
\text { value }
\end{array}\right.
$$

\section{Clinical variables}

$\mathrm{BMI}(\mathrm{kg} / \mathrm{m} 2)$ mean (SD) $\quad 30.18(5.99)$

Glom. F (ml/min) mean (SD) $69.54(19.10)$

Hemoglobin $(\mathrm{mg} / \mathrm{dL})$ mean $13.99(1.82)$

$(\mathrm{SD})$

Hypertension

Tobacco use

Diabetes mellitus

Dyslipidemia

Ischemic disease

Valvular disease

Stroke

CHA2DS2-VASC

PACE Calc (\% at 3 y) mean

(SD)

\section{Polysomnography variables}

Snorer

Epworth mean (SD)

IAH mean (SD)

CT90\% mean (SD)

\section{Echocardiography variables}

LAD (mm) mean (SD)

LAS (cm2) mean (SD)

LA dilatation

$21(43.7 \%)$

$8.92(4.45)$

$34.60(20.34)$

$20.38(29.48)$

$2.7(1.6)$

$2.7(1.5)$

14.73

(14.28)

\begin{tabular}{lll}
\hline $31.84(5.94)$ & $29.04(5.91)$ & 0.300 \\
$\begin{array}{l}70.30 \\
(16.34)\end{array}$ & $68.96(21.29)$ & 0.790 \\
\hline $14.21(1.94)$ & $13.82(1.74)$ & 0.379 \\
\hline $14(66.7 \%)$ & $20(74.1 \%)$ & 0.750 \\
$10(47.6 \%)$ & $14(51.8 \%)$ & 0.482 \\
\hline $6(28.6 \%)$ & $10(37 \%)$ & 0.758 \\
$12(57.1 \%)$ & $10(37 \%)$ & 0.244 \\
$3(14.3 \%)$ & $7(25.9 \%)$ & 0.478 \\
$1(4.7 \%)$ & $1(3.7 \%)$ & 1 \\
\hline $0(0 \%)$ & $1(3.7 \%)$ & 1 \\
\hline $2.7(1.5)$ & $2.7(1.7)$ & 1 \\
\hline $\begin{array}{l}14.73 \\
(14.28)\end{array}$ & $24.41(21.88)$ & 0.104 \\
\hline
\end{tabular}

AF: atrial fibrillation; AFL: atrial typical flutter; AT: atrial tachycardia; BMI: body mass index; HM: 24hholter monitoring; LA: left atrium; LAD: left atrium diameter; LAS: left atrium surface; LVEF: left ventricle ejection fraction; LVH: left ventricle hypertrophy; SV: supraventricular.
$9(42.9 \%) \quad 12(44.4 \%) \quad 1$

$7.58(4.12)$

$10.07(4.55)$

0.165

32.83

(14.89)

$36.01(24.28)$

0.961

33.88

(37.70)

$8.80(12.50)$

0.060 


\begin{tabular}{|c|c|c|c|c|}
\hline & $\begin{array}{l}\text { Total AFL group }(n= \\
\text { 48) }\end{array}$ & $\begin{array}{l}\text { No AF }(n= \\
21)\end{array}$ & $\begin{array}{l}\text { New onset AF }(n= \\
27)\end{array}$ & $\begin{array}{l}\mathrm{p} \text { - } \\
\text { value }\end{array}$ \\
\hline LVEF (\%) mean (SD) & $52.59(11.71)$ & $\begin{array}{l}52.63 \\
(14.23)\end{array}$ & $52.57(9.94)$ & 0.875 \\
\hline LVEF $<55 \%$ & $18(37.5 \%)$ & $8(38.1 \%)$ & $10(37 \%)$ & 1 \\
\hline LVH & $15(31.2 \%)$ & $7(33.3 \%)$ & $8(29.6 \%)$ & 1 \\
\hline \multicolumn{5}{|l|}{ Electrical variables } \\
\hline $\begin{array}{l}\text { AH interval (msec) mean } \\
\text { (SD) }\end{array}$ & $115.59(32.53)$ & $\begin{array}{l}112.00 \\
(21.84)\end{array}$ & $117.55(37.98)$ & 1 \\
\hline $\begin{array}{l}\text { HV interval (msec) mean } \\
\text { (SD) }\end{array}$ & $51.77(8.40)$ & $48.00(5.25)$ & $54.13(9.25)$ & 0.092 \\
\hline $\begin{array}{l}\text { PR interval (msec) mean } \\
\text { (SD) }\end{array}$ & $180.27(44.38)$ & $\begin{array}{l}177.48 \\
(57.02)\end{array}$ & $184.67(31.39)$ & 0.589 \\
\hline $\begin{array}{l}\text { QRS duration (msec) mean } \\
\text { (SD) }\end{array}$ & $112.48(25.19)$ & $\begin{array}{l}112.14 \\
(24.93)\end{array}$ & $112.74(25.86)$ & 0.975 \\
\hline SV ectopy $>02 \%$ at $24 \mathrm{~h}-\mathrm{HM}$ & $13(27.1 \%)$ & $5(23.8 \%)$ & $8(29.6 \%)$ & 0.750 \\
\hline Atrial tachycardia at $24 \mathrm{~h}-\mathrm{HM}$ & $16(33.3 \%)$ & $4(19 \%)$ & $12(44.4 \%)$ & 0.075 \\
\hline $\begin{array}{l}\text { SV ectopy }>0,2 \% \text { or AT at } \\
24 \mathrm{~h}-\mathrm{HM}\end{array}$ & $23(47.9 \%)$ & $6(28.6 \%)$ & $17(63 \%)$ & 0.023 \\
\hline
\end{tabular}

Univariate analyses demonstrated a clear trend, although not significant, for SVE (HR 2.14, 95\% Cl: 0.984.68; $p=0.057)$. Among continuous variables the $H V$ interval was the only predictor for new onset $A F$, with a HR $1.08(95 \% \mathrm{Cl}: 1.01-1.16 ; p=0.026)$. The PACE calculator revealed a trend towards predicting $A F,(H R$ $1.02,95 \% \mathrm{Cl}: 1-1.03 ; p=0.1$ ).

Given the fact that SVE is included in the PACE calculator and that SVE and HV interval showed a limited discrimination potential as continuous variables, we carried out a new analysis using the PACE calculator and $\mathrm{HV}$ interval as categorical variables (Table 4). Multivariate analyses showed that a PACE calculator score of $\geq 30 \%$ predicted the occurrence of new onset AF at a median follow-up of 12 months (Q1-Q3: 419 months), with a HR of 6.9 ( $95 \% \mathrm{Cl}: 1.71-27.91 ; p=0.007)$ and $\mathrm{HV}$ interval of $\geq 55 \mathrm{msec}$ predicted the occurrence of new onset AF with a HR of 11.86 (95\% Cl: 2.57-54.8; $\mathrm{p}=0.002)$. Interestingly LA dilatation did not predict $A F$ incidence in our population. Figure 3shows survival curves for freedom from AF incidence related to the PACE calculator score and HV interval, respectively, in patients with previously ablated AFL. 
Table 4

Multivariate analysis of predictors for AF in patients who had AFL ablation

\begin{tabular}{|lll|}
\hline & HR $(95 \%$ IC & p-value \\
\hline PACE calculator $\geq 30$ & $6,9[1,71 ; 27,91]$ & 0.007 \\
\hline HV interval $>55$ & $11,86[2,57 ; 54,83]$ & 0.002 \\
\hline Hypertension & $2,27[0,67 ; 7,73]$ & 0.191 \\
\hline LVH & $0,66[0,24 ; 1,82]$ & 0.421 \\
\hline LA dilatation & $0,47[0,14 ; 1,58]$ & 0.220 \\
\hline Ischemic disease & $0,43[0,1 ; 1,89]$ & 0.262 \\
\hline Glom. F. (ml/min) & $1,01[0,99 ; 1,04]$ & 0.345 \\
\hline QRS duration (msec) & $0,99[0,97 ; 1,02]$ & 0.535 \\
\hline Hemoglobin (mg/dL) & $0,88[0,67 ; 1,16]$ & 0.371 \\
\hline AF: atrial fibrillation; AFL: atrial typical flutter; LA: left atrium; LVH: left ventricle hypertrophy \\
\hline
\end{tabular}

\section{Predicting high-risk patients}

We analyzed the added value of considering the PACE calculator score and/or HV interval in order to better stratify the risk for new onset $A F$ in patients undergoing an AFL ablation procedure. Concerning the PACE calculator, a score of $\geq 30 \%$ predicted the incidence of new onset AF during follow-up with a specificity of $90.5 \%$, a sensitivity of $38.5 \%$, a positive predictive value (PPV) of $83.3 \%$ and a negative predictive value (NPV) of $54.3 \%$. Regarding the HV interval, a value of $\geq 55 \mathrm{msec}$ predicted the incidence of new onset AF during the follow-up with a specificity of $88.9 \%$, a sensitivity of $62.5 \%$, a positive predictive value (PPV) of $88.2 \%$ and a negative predictive value (NPV) of $64 \%$. Therefore if the PACE score was $\geq 30$ or the HV was $\geq 55 \mathrm{msec}$, the probability of developing AF at a median of 12 months follow-up was greater than $83 \%$ and $88 \%$, respectively. Figure 4 shows area under ROC curve to predict new onset $A F$ in patients with $A F$ with PACE calculator score $\geq 30$ or with $H V$ interval $\geq 55 \mathrm{msec}$, respectively. Finally when combining both variables, the NPV of having a PACE calculator score of $<30$ and an HV interval of $<55 \mathrm{msec}$ was $75 \%$ (95\% Cl: 50.9\%-91.3\%).

\section{Discussion}

\section{Typical flutter as a risk factor for AF}

New onset AF can be observed in a high proportion of patients after an AFL ablation [4-13] but studies addressing this issue are retrospective and most of them are based on 24-h holter monitoring, and it is well known that AF detection increases with more frequent and continuous monitoring $[8,9]$. We prospectively included seventy patients and monitored them continuously with ILR or CDAL. It was expected that the patients with AFL had less comorbidities and lower PACE scores than the patients 
without AFL, as they were enrolled solely for a history of AFL undergoing ablation. We found that the presence of AFL was associated with a much more increased risk that we expected for developing new onset AF when compared to other known clinical risk factors (56.3\% with AFL vs $22.7 \%$ without $A F L, p=$ 0.011). Atrial flutter was the only independent predictor for new onset AF at median follow-up of 12 months (Q1-Q3: 4-19 months; HR: 3.82; 95\% Cl: 1.46-10.03; $p=0.006)$ follow-up, with an incidence of more than $56 \%$. Despite several prior studies demonstrating a high incidence of new onset AF after AFL ablation, the findings of this study are unique in that it is the first prospective study evaluating clinical and noninvasive variables, as well as invasive data from electrophysiological studies. This data confirms the link between AFL and development of new onset AF, but suggests it is even stronger than previously believed, probably due to the presence of advanced substrate for AF. It is likely that the high incidence of new onset AF in this study is due to both the high risk profile of patients included (average CHA2DS2VASC score of 3.2) and the use of continuous long-term monitoring with ILR or CDAL in all patients.

\section{Very high-risk patients}

Several variables have been described to predict new onset AF occurrence after AFL ablation. A large retrospective study included patients with and without previous AF [6], and correlated LA enlargement with the occurrence of new onset AF, but with a limited HR of 1.058 [7]. We did not find any association between LA enlargement and new onset AF but the limited size of our population could have influenced the results. The presence of advanced interatrial block, which is linked to LA enlargement [10], has been also described as a predictor for new onset AF in patients with AFL. This parameter is useful since it can be observed in a 12-lead ECG. Unfortunately we did not collect this information. Instead we collected the PR interval, which takes part in the PACE calculator, and other surface and intracardiac electrophysiological parameters such as QRS duration, AH interval and HV interval. We found a PACE calculator score of $\geq 30 \%$ and/or an $\mathrm{HV}$ interval of $\geq 55 \mathrm{msec}$ to be the only, but strong predictors for new onset $\mathrm{AF}$ at follow-up. This finding reinforces the PACE calculator as a useful tool to predict AF in the general population as well as to further risk stratify patients after AFL ablation, since it behaved as independent predictor, providing additional and complimentary information. Of importance the PACE calculator includes significant atrial ectopy as a predictor, which was associated to new onset AF at follow-up in the general population. We could not find any other predictor, including left atrium dilatation or OSAS. Finally we found that both a high PACE calculator score and/or a long HV interval are very specific predictors for new onset AF in this subset of patients, with a very good PPV. Concerning our findings with the HV interval, this parameter has been previously correlated inversely with the left ventricular ejection fraction in patients with structural heart disease [19], and an HV interval of $\geq 55 \mathrm{msec}$ has also been associated to atrial arrhythmias [20]. Given that patients with isolated AFL develop not only new onset AF but also stroke [21] at a higher rate than general population we believe that both variables could be of help in the decision for rigorous monitoring for $\mathrm{AF}$ and even in the decision for longterm anticoagulation in determinate cases: if either the PACE score is $\geq 30$ or the HV interval is $\geq 55 \mathrm{msec}$, the probability of developing AF at a median of 12 month follow-up is greater than $83 \%$ and this would favor the decision of not to stop anticoagulation after AFL ablation; on the other hand if both, the PACE 
calculator score and the $\mathrm{HV}$ interval, are below those limits, the probability maintaining sinus rhythm is $75 \%$, indicating that discontinuation of anticoagulation would be probably safe.

Interestingly, some centers have performed prophylactic pulmonary vein isolation in patients with AFL but without documented AF [22,23]. Results have revealed a significant reduction in recurrent atrial arrhythmias. From our point of view such a strategy could be of use in individualized high-risk cases, namely young patients with AFL with a high PACE calculator score or long HV interval, but this should be assessed in a prospective randomized study.

\section{Limitations}

It is likely that the high incidence of new onset AF in this study is due to both the high risk profile of patients included (average CHA2DS2-VASC score of 3.2) and the use of continuous long-term monitoring with ILR or CDAL in all patients. This study may have been limited by the small sample size, which may have accounted for the lack of predictive value of left atrial dilation or sleep apnea. Importantly despite this inconvenience we have been able to reach the two most relevant independent predictors for new onset AF in this setting of previous AFL ablation. This should be complemented with further research of predictors in a more extensive sample size.

\section{Conclusions}

In summary, we find that AFL is the most important predictor for new onset AF in a prospective study evaluating comprehensive clinical, noninvasive and invasive electrophysiological parameters, with longterm continuous cardiac monitoring. Patients with AFL have even greater risk for AF than patients with significantly increased comorbidities, traditional risk factors for AF, and higher PACE calculator score. Additionally, in patients who undergo AFL ablation, a high PACE score or long HV interval predicts very high risk for developing AF. These patients should be considered for rigorous monitoring for AF or even for empiric long-term anticoagulation in determinate cases. A large prospective randomized trial should be performed in order to confirm these findings.

\section{References}

1. Pérez FJ, Schubert CM, Parvez B, Pathak V, Ellenbogen KA, Wood MA. Long-term outcomes after catheter ablation of cavo-tricuspid isthmus dependent atrial flutter: a meta-analysis . Circ Arrhythm Electrophysiol. 2009;2(4):393-401

2. Vallès E, Bazan V, Cainzos-Achirica M, Jáuregui ME, Benito B, Bruguera J, Martí-Almor J. Incremental pacing maneuver for atrial flutter recurrence reduction after ablation: Vallès: yield of incremental pacing after flutter ablation. Int J Cardiol. 2014;177(3):902-6

3. Jiménez-López J, Vallès E, Martí-Almor J, González-Matos C, Bas D, Benito B, Alcalde, et al. Mapping potentials adjacent to the cavo-tricuspid isthmus ablation line during incremental pacing: A feasible 
and highly accurate maneuver to confirm complete CTI conduction block. J Cardiovasc Electrophysiol. 2020;31(7):1649-1657

4. Bianco I, Silva GOD, Forno ARJD, Nascimento HG, Lewandwoski A, Pereira E, d'Avila A. Risk of Atrial Fibrillation after Ablation of Cavotricuspid Isthmus-Dependent Atrial Flutter: Is Combined Ablation of Atrial Fibrillation Worthwhile? Arq Bras Cardiol. 2020;114(5):775-782

5. Warchoł I, Bińkowski BJ, Kucejko T, Sobiczewska J, Lubiński A. A Retrospective Study of Atrial Fibrillation Following Cavotricuspid Isthmus Ablation for Atrial Flutter. Med Sci Monit. 2019;25:33163320

6. García-Seara J, Gude Sampedro F, Martínez Sande JL, Fernández López XA, Rodríguez Mañero M, González Melchor L, Alvarez Alvarez B, et al. Is HATCH score a reliable predictor of atrial fibrillation after cavotricuspid isthmus ablation for typical atrial flutter? Int J Cardiol Heart Vasc. 2016;12:88-94

7. Celikyurt U, Knecht S, Kuehne M, Reichlin T, Muehl A, Spies F, Osswald S, et al. Incidence of new-onset atrial fibrillation after cavotricuspid isthmus ablation for atrial flutter. Europace. 2017;19(11):17761780

8. Maskoun W, Pino MI, Ayoub K, Llanos O, Almomani A, Nairooz R, Hakeem A, et al. Incidence of Atrial Fibrillation After Atrial Flutter Ablation. JACC Clin Electrophysiol. 2016;2(6):682-690

9. Voight J, Akkaya M, Somasundaram P, Karim R, Valliani S, Kwon Y, Adabag S. Risk of new-onset atrial fibrillation and stroke after radiofrequency ablation of isolated, typical atrial flutter. Heart Rhythm 2014;11(11):1884-9

10. Enriquez A, Sarrias A, Villuendas R, Ali FS, Conde D, Hopman WM, Redfearn DP, et al. New-onset atrial fibrillation after cavotricuspid isthmus ablation: identification of advanced interatrial block is key. Europace. 2015;17(8):1289-93

11. Henmi R, Ejima K, Shoda M, Yagishita D, Hagiwara N. Interatrial Conduction Time Can Predict NewOnset Atrial Fibrillation After Radiofrequency Ablation of Isolated, Typical Atrial Flutter. J Cardiovasc Electrophysiol. 2016;27(11):1293-1297

12. Chen K, Bai R, Deng W, Gao C, Zhang J, Wang X, Wang S, et al. HATCH score in the prediction of newonset atrial fibrillation after catheter ablation of typical atrial flutter. Heart Rhythm. 2015;12(7):14839

13. Romero J, Estrada R, Holmes A, Goodman-Meza D, Díaz JC, Briceño D, Kumar S, et al. Atrial fibrillation inducibility during cavo-tricuspid isthmus dependent atrial flutter ablation for the prediction of clinical atrial fibrillation. Int J Cardiol. 2017;240:246-250

14. Bazan V, Grau N, Valles E, Felez M, Sanjuas C, Cainzos-Achirica M, Benito B, et al. Obstructive sleep apnea in patients with typical atrial flutter: prevalence and impact on arrhythmia control outcome. Chest. 2013;143(5):1277-1283

15. Cabrera $S$, Vallès E, Benito B, Alcalde 0 , Jiménez J, Fan R, Martí-Almor J. Simple predictors for new onset atrial fibrillation. Int J Cardiol. 2016;221:515-20

16. Vallès E, Bazán V, Benito B, Jáuregui ME, Bruguera J, Guijo MA, Altaba C, et al. Incremental His-tocoronary sinus maneuver: a nonlocal electrogram-based technique to assess complete cavotricuspid 
isthmus block during typical flutter ablation. Circ Arrhythm Electrophysiol. 2013;6(4):784-9

17. Bazan V, Martí-Almor J, Perez-Rodon J, Bruguera J, Gerstendeld EP, Callans DJ, Marchlinski FE. Incremental pacing for the diagnosis of complete cavotricuspid isthmus block during radiofrequency ablation of atrial flutter. J Cardiovasc Electrophysiol. 2010;21(1):33-9

18. Vallès E, Cabrera S, Benito B, Alcalde O, Jiménez J, Martí-Almor J. Burning the Gap: Electrical and Anatomical Basis of the Incremental Pacing Maneuver for Cavotricuspid Isthmus Block Assessment. J Cardiovasc Electrophysiol. 2016;27(6):694-8

19. Rasmussen K, Thomsen PE, Bagger JP. HV interval in calcific aortic stenosis. Relation to left ventricular function and effect of valve replacement. Br Heart J. 1984;52(1):82-6

20. Barbhaiya CR, Kumar S, Baldinger SH, Michaud GF, Stevenson WG, Falk R, John RM. Electrophysiologic assessment of conduction abnormalities and atrial arrhythmias associated with amyloid cardiomyopathy. Heart Rhythm. 2016;13(2):383-90

21. Gula LJ, Redfearn DP, Jenkyn KB, Allen B, Skanes AC, Leong-Sit P, Shariff SZ. Elevated Incidence of Atrial Fibrillation and Stroke in Patients With Atrial Flutter-A Population-Based Study. Can J Cardiol. 2018;34(6):774-783

22. Mohanty S, Natale A, Mohanty P, Di Biase L, Trivedi C, Santangeli P, Bai R, et al. Pulmonary Vein Isolation to Reduce Future Risk of Atrial Fibrillation in Patients Undergoing Typical Flutter Ablation: Results from a Randomized Pilot Study (REDUCE AF). J Cardiovasc Electrophysiol. 2015;26(8):819825

23. Steinberg JS, Romanov A, Musat D, Preminger M, Bayramova S, Artyomenko S, Shabanow V, et al. Prophylactic pulmonary vein isolation during isthmus ablation for atrial flutter: the PReVENT AF Study I. Heart Rhythm 2014;11(9):1567-72

\section{Figures}




\section{PACE Atrial Fibrillation Calculator}

P R Interval (100-400):

240

A ge (30-100):

75

C ardiomyopathy / Heart Failure:

Yes

- No

E ctopy (supraventricular) $>0.2 \%$ :

- Yes

No

\section{Calculate Result}

2 Years AF probability:

3 Years AF probability:
$17.6 \%$

$27.34 \%$

Figure 1

Example of the 2 and 3 years new onset AF risk calculation by means of PACE calculator from the website. 


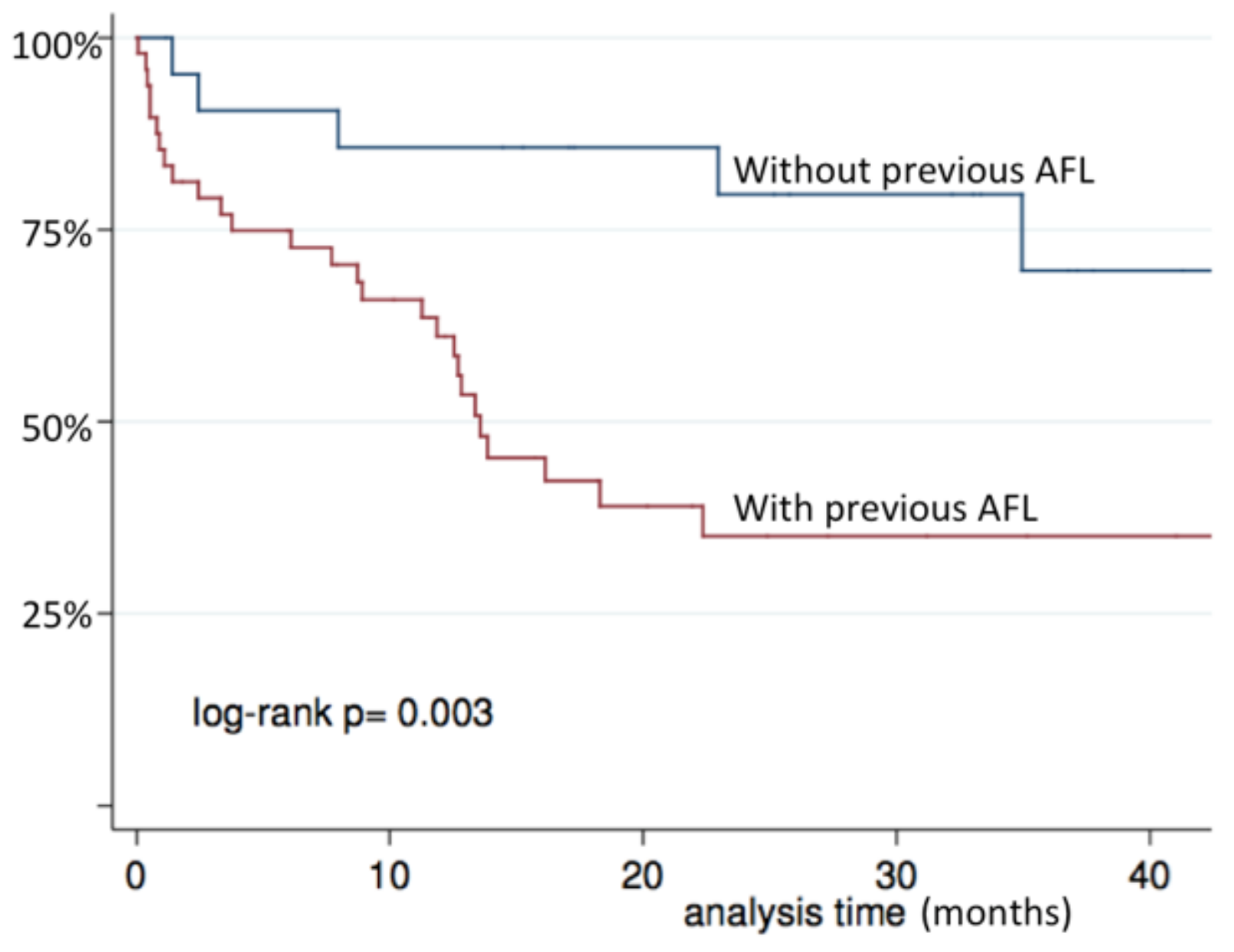

Figure 2

Freedom from AF depending on the presence of previous AFL Figure displays survival analyses for freedom from AF incidence depending on the presence of previous AFL. Blue and red lines show survival for patients without and with previous AFL, respectively. AF: atrial fibrillation; AFL: typical atrial flutter
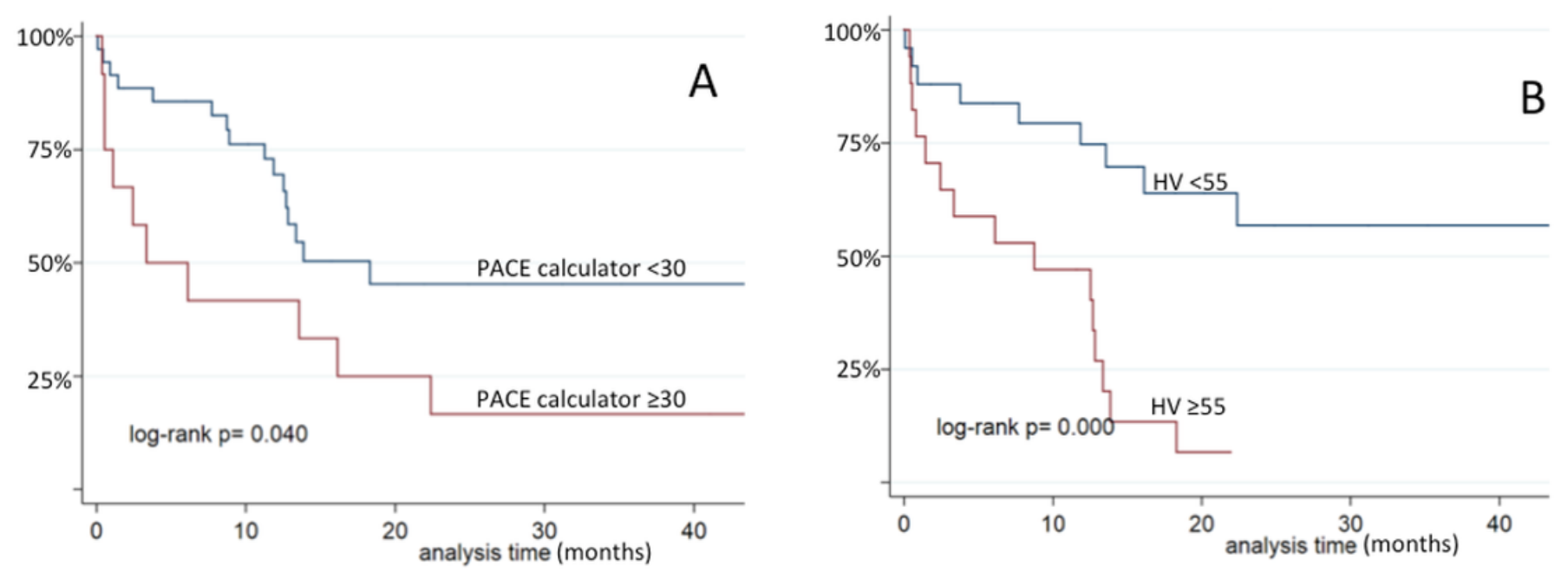

Figure 3 
Survival analyses for freedom from AF depending on PACE calculator score and $\mathrm{HV}$ interval in patients with previous AFL Figure shows survival analyses for freedom from AF incidence depending on PACE calculator score (A) and depending on $\mathrm{HV}$ interval $(B)$ in patients with previously ablated AFL. AF: atrial fibrillation; AFL: typical atrial flutter
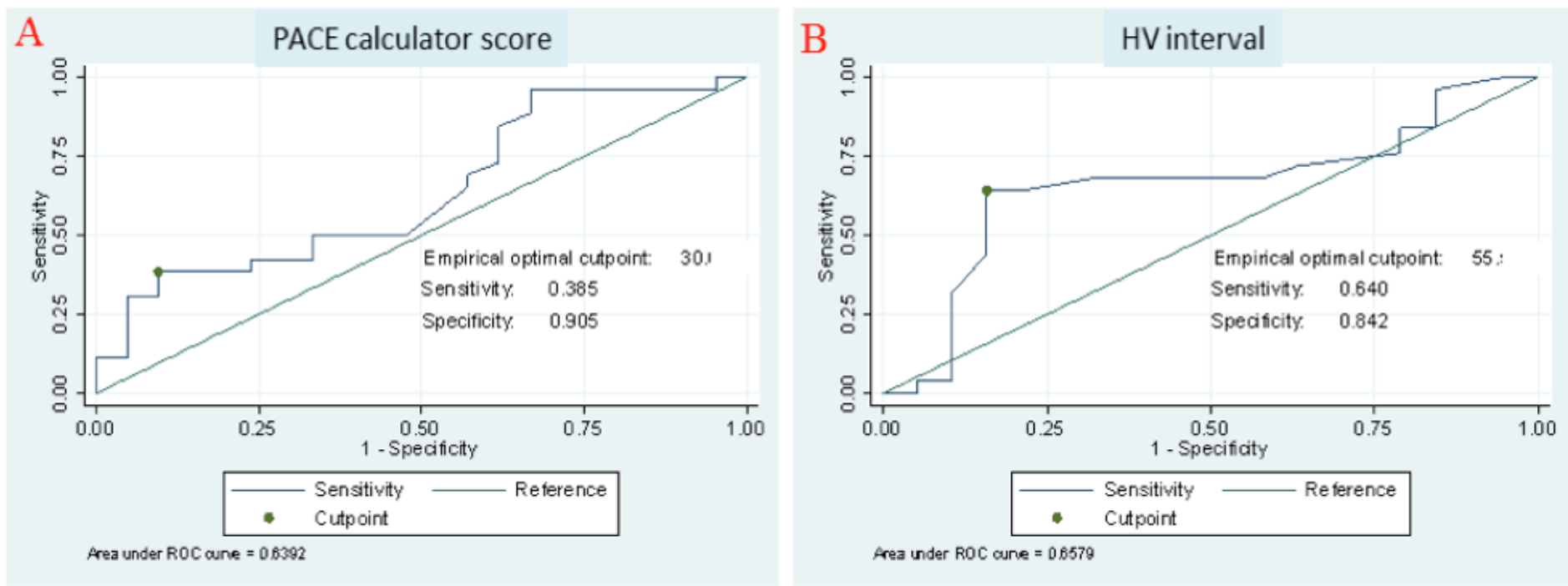

\section{Figure 4}

Area under ROC curve to predict new onset $A F$ in patients with AFL Figure shows area under ROC curve for a PACE calculator score $\geq 30(A)$ and for an $\mathrm{HV}$ interval $\geq 55 \mathrm{msec}(B)$ to predict new onset $A F$ in patients with AFL. AF: atrial fibrillation; AFL: typical atrial flutter 